\title{
NATURE INDOOR
}

\author{
Evren SELÇUK*, Seniha ÜNAY SELÇUK ${ }^{* 1}$ \\ * Dr. Öğr. Üyesi, Düzce Üniversitesi Sanat Tasarım ve Mimarlık Fakültesi, Heykel Bölümü \\ ** Doç. Dr. Düzce Üniversitesi Sanat Tasarım ve Mimarlık Fakültesi, Resim Bölümü²
}

\begin{abstract}
This study aims to examine the artworks that are examples of displaying nature indoors. As a consequence of these works being more visible in art during the 1960's and later periods, the study has been limited to living artists and their artworks of the 1960's and the later periods.

In this context; Richard Long proposer of making art in nature as opposed to the gallery system, who nevertheless presents his works in galleries, Roxy Paine, the imitator of nature without compromise to the original, who shows us artificial scenes from nature in indoor spaces with a persuasive visual quality and Olafur Eliasson who can reflect the outdoors nature without losing any features of its magnificence in indoor spaces were discussed. Because the chosen artists had shaped the periods in which they lived, environmental and ecologic instances were focused on. It was seen that after this periods the artists started to use a more reactive and harsh language and that they were observing nature even more deeply and in detail.

It was seen in Richard Long, Roxy Paine, and Olafur Eliasson that they realized their works with a manner that knew and recognized the nature and with a sensitivity they developed towards it. It was also observed that they made use of current expression opportunities and display methods and that they emphasized the power of nature, nature's complexity, and natural systems in their works. When the ideas that gave life to their works were analyzed, it was concluded that the way the artists perceived and interpreted nature was determinant on the manifestation of nature in their art.

During the process of the research a scan of libraries, archives and periodical publications was done alongside an analysis and data gathering process; in which artist's websites were examined and ideas of art critics, art historians and artists were benefited from.
\end{abstract}

Keywords: Nature, Art, Richard Long, Roxy Paine, Olafur Eliasson

\section{IÇERIDEKI DOĞA}

\section{Özet}

$\mathrm{Bu}$ çalışmanın amacı, doğanın iç mekânda sergilenmesine örnek teşkil eden sanat yapıtlarının incelenmesidir. Bu örneklerin, 1960'lar ve sonrası sanatta daha görünür olmasından hareketle; çalışma 1960'lar ve sonrası süreçte yaşayan sanatçılar ve yapıtlarıyla sınırlandırılmıştır.

Bu bağlamda, galeri sistemine karşı doğada sanat yapma önerisine rağmen çalışmalarını yine de galerilerde sergileyen Richard Long, inandırıcılığından taviz vermeden doğayı taklit eden ve ikna edici bir görsellikle iç mekânda yapay doğa kesitleri sunan Roxy Paine ve dışarıdaki doğayı, intişamından bir şey kaybettirmeden iç mekânda gösterebilen yapıtlarıyla Olafur Eliasson ele alınmıştır. Seçilen sanatçıların yaşadığı dönemi şekillendirdiği sebebiyle çevresel ve ekolojik olaylar üzerinde durulmuştur. Bu dönemden sonra sanatçıların bu olaylara karşı daha tepkisel ve sert bir dil kullandıkları, doğaya daha derin ve detaylı baktıkları görülmüştür.

Richard Long, Roxy Paine ve Olafur Elliasson'un doğayı bilen, tanıyan bir tavırla, doğaya dair duyarlıkla yapıtlar gerçekleştirdikleri, güncel ifade olanaklarından ve sergileme yöntemlerinden faydalandıkları; yapıtlarında doğanın gücü, doğanın karmaşıklığı ve doğa sistemleri üzerinde durdukları görülmüştür.

\footnotetext{
${ }^{1}$ Sorumlu Yazar email: senihaunay@gmail.com / Doi: 10.22252/ijca.749369
} 
Yapıtlarını oluşturan kavramsal süreçleri incelendiğinde ise; doğayı algılama ve yorumlama biçimlerinin yine yapıtlarında doğayı baskın hale getirdiği sonucuna varıımıştır.

Çalışma süresince sanat alanında kütüphane, arşiv ve süreli yayınlardan tarama, inceleme ve veri toplama işlemi yapılmış; sanatçı web siteleri incelenmiş; sanat eleştirmeni, sanat tarihçisi ve sanatçıların düşüncelerinden faydalanılmıştır.

Anahtar Kelimeler: Doğa, Sanat, Richard Long, Roxy Paine, Olafur Eliasson

\section{Giriş}

Doğa yüzyıllardır farklı alanların malzemesi olarak ele alınmaktadır. Burada bahsedilen doğa, kendiliğinden var olan, değişen, dönüşen tabiattır. Doğanın, sanatın da önemli bir malzemesi olarak işlendiği, sanatçıların çok sık başvurduğu adreslerden biri olduğu söylenebilir. Doğanın sanatta temsil, kopya, imge, yanılsama ve fon olarak bazı dönemler geri planda, bazı dönemlerse ön planda tutulduğu; örneğin, Rönesans ve öncesinde, Maniyeristlerde, Barok dönemde, Rokoko'da, Çin ve Japon manzara resimlerinde; İzlenimciler, Gerçekçiler ve Dışavurumcuların çalışmalarında sıklıkla yer aldığı geçmişten günümüze sanat yapıtları incelendiğinde görülebilir. Özellikle 1960'lar ve sonrası doğanın, sanattaki temsil biçimlerinden birinin doğanın kendisi olarak iç mekâna taşınması olduğu söylenebilir. Buradan hareketle, bu çalışmanın kapsamını doğanın iç mekânda olduğu gibi gösterildiği yapıtlar, yapıtların zeminini oluşturan nedenler ve sanatçılarının incelenmesi oluşturmaktadır.

Her dönem sanatta doğanın var olma biçimlerinin; dönemin ruhu, sanat dinamikleri, toplumsal, ekonomik ve politik etkenler ile çevre ve ekolojik konular çerçevesinde değişiklik gösterdiği söylenebilir. Bu sebeple bu çalışma sayılan etkenlerin en yoğun yaşandığı dönem olduğu düşüncesiyle 1960'lar ve sonrasıyla sınırlandırılmıştır.

Bu kapsamda metin bu dönemin ruhunu ve sanatçıların doğaya karşı tutumunu anlatabilmek için John Berger'in "Beyaz Kuş" pasajındaki kötülüğün varlığı ve sanat örgütlü bir tepkiselliktir sözleri ile başlamaktadır. Ardından 20. yüzyılın ikinci yarısında hızlanan çevre sorunları, doğa odaklı sanat çalışmalarını o zamandan bugüne şekillendirdiği düşüncesiyle ele alınmaktadır. Bu sürece tanık olmuş, yapıtlarını bu süreçte üretmiş, halen yaşayan, yapıtları güncel bir sergide görülebilecek sanatçılardan Richard Long, Roxy Paine ve Olafur Eliasson'un doğayı gerçek bir kesit olarak iç mekâna taşıdıkları sanat yapıtları, sergileme yöntemleri üzerinde durulmaktadır. Bu üç sanatçının yapıtlarını ele almak; doğanın çağdaş sanatta nasıl temsil edildiğine örnek oluşturacak olması, değişen sergileme biçimlerine yeniden bakılması ve doğa üzerine bir farkındalık oluşturması açısından önemli görülmektedir.

Çalışmada Richard Long'un "Kırmızı Arduvaz Çemberi” ve "Dört Yol” çalışmaları; Roxy Paine'in "Zehirli Sarmaşık Tarlası", "Ota Boğulmuş Bahçe" ve Ekin (Afyon Çiçekleri) çalışmaları; Olafur Eliasson'un "Nehir Yatağı", "Sarı Orman", "Hava Projesi" çalışmaları, içerik ve biçim açısından incelenmektedir. Yapıt okumaları sanat eleştirmenleri, sanat yazarları, sanat tarihçilerinin düşünceleri üzerinden yapılmaktadır.

\section{Umut ilkesi, kötülüğün varlığı ve tepkisellik}

"Güzel olan eski şeylerden değil, kötü olan yeni şeylerden yola çıkın" (Bertol Brecht'ten akt. Benjamin, 2018)

John Berger (2019:206-209) "Beyaz Kuş" Pasajına umut ilkesi ve kötülüğün varlığından konuşmadan estetikten bahsedilemez diye başlar. İnsanın doğayı bir arenaya, bir sahneye dönüştürecekse iyilik kadar kötülüğe de meydan vermesi gerektiğini söyler ve ekler: "Sanat doğaya öykünmez, yaratılışa öykünür - kâh başka bir dünya önermek için, kâh doğanın sunduğu o kısacık vaat ânını büyütmek, onaylamak, 
INONU UNIVERSITY JOURNAL OF CULTURE AND ART / IJCA

İnönü Üniversitesi Kültür ve Sanat Dergisi

Volume/Cilt: 6 No/Sayı: 1 (2020) 14-26

toplumsallaştırmak için. Sanat, doğanın ancak zaman zaman göz ucuyla bize gösterdiği şey karşısında verilmiş örgütlü bir tepkidir".

Beyaz Kuş pasajı, doğadan bir parçaya (iç mekâna asılan tahta kuş) dair görüşümüzü, bir doğa parçasına dair estetik deneyimimizi, doğanın gücünü, doğanın sanatla olan ilişkisini özetler. Bunun yanı sıra sanatın örgütlü bir tepki olma refleksine işaret eder. Bu tepkisellik doğa odaklı bir anlayış olarak, felsefik ve sanatsal bir akım olan Romantizm'le ilişkilendirilebilir. Romantizm, hem doğaya övgüyü hem de doğaya karşı bir müdahale haline gelen toplumsal ve politik olaylara karşı verilen tepkiyi içinde barındırır. "...romantiklerin doğa vurgusunun sebebi yüzyılın sonunda patlak veren endüstriyel kapitalizmle su, rüzgâr ve fosil yakıtlar gibi doğal kaynakların kullanılmaya başlanması, şehirlerin genişleyip kirlilik, sefillik ve yoksunluk merkezlerine dönüşmesidir" (Turan, 2016).

Romantiklerin doğa vurgusunun sebebinin, 1960'lar ve sonrasında daha yoğun hissedildiği, bu dönemden sonra yaşanan toplumsal, ekonomik, politik olaylara; çevresel ve ekolojik sorunlara karşı sanatçıların sert ve eleştirel bir dil geliştirdikleri söylenebilir. Bu tepkisel dille birlikte doğa, daha belirgin ve daha derin olarak sanatsal çalışmalarda yerini alır. Örneğin arazi sanatı dünyanın ticarileşmesine karşı bir tepki ve doğayla primitif bir duyguyla yeniden bağ kurma girişimine; eko sanat insanlığın doğanın doğal sürecine müdahale etmesine karşı duyulan kaygıya; biyo sanat ise doğanın genetiği ve evrim sürecinde bilimsel ve teknolojik gelişmelerle doğa üzerinden etik sorunlara odaklanır (Leppert, 2017). Bu süreci şekillendiren yapıtlar arasındaysa Joseph Beuys'un "Sosyal Heykel” kavramı, Yoko Ono'nun Gökyüzü TV'si, Walter De Maria'nın doğal afetlerle ilgili gerçekleştirdiği çalışmaları, Jackie Brookner'in "biyo heykel" kavramıyla açıkladığı ekosistemi, Helen Mayer Harrison ve Newton Harrison'un ekolojik projeleri gibi yapıtlar sayılabilir.

"Sanayi devrimiyle artı̧̧ kazanan hava kirliliği, 20. yüzyılda doğal çevreyi, atmosferi geri dönülemez biçimde tahrip eder boyutlara ulaşmıştır (Çoşkun, 2019:15). Özellikle 2. Dünya Savaşı sonrası bilim ve teknoloji alanındaki yanlış politikalar, sanayileşmenin olumsuz etkilerini artırmış ve doğanın kirlenmesini hızlandırmıştır. Buna paralel olarak 1960'larda başlayan öğrenci hareketlerinin de çevre faktörleri üzerine şekillendiği görülmektedir. 1971 yılında "Doğayı odağına alan ve sürdürülebilir bir yaşam için mücadele ediyoruz. Bunun için, çevre suçlarına karşı tanıklık ediyor, bilimsel çalışmalar yürütüyor, çözümler üretiyoruz" sloganıyla hareket eden Greenpeace'in kurulması tesadüf değildir (Greenpeace, 2020).

1973'te Arap-İsrail Savaşı'nın ardından petrol fiyatlarının artmasıyla ortaya çıkan OPEC Petrol krizi de ileride petrol sızıntılarıyla çevre sorunlarına sebep olacak petrolün fazla tüketilmesinin ilk sinyalleri gibidir. 1986 yılında Çernobil'de yaşanan nükleer patlama, yine dönemin çevreci ruhunu harekete geçiren olaylardan olmuştur. İnsanın doğaya verdiği zarar, bazı canlı türlerinin neslinin tükenmesi, ozon tabakasının delinmesi, genetiği değiştirilmiş canlı ve gıdaların artması şeklinde bugün daha yoğun hissedilmektedir. Örneğin insan faaliyetleri sonucu ortaya çıkan küresel iklim değişikliğine bağlı iklim mülteciliğinin Myers'e göre 2050 yılına kadar 200 milyon olacağı tahmin edilmektedir (Madra, 2017). Bu ve benzeri şekillerde ve nedenlerle doğanın tahrip edilmesi insanlığın görmezden gelemeyeceği boyutlara ulaşmıştır. Walter Truett'in dediği gibi, "Doğadan kastettiğiniz şey, Dünya yüzeyinin insan faaliyetlerinden etkilenmemiş bir parçası ise, bunu unutun. Öyle bir ekosistem yok, öyle bir hayvan yok, öyle bir yer yok -olmayalı da uzun zaman oldu" (Walter Truett: 1996:185; akt. Wallace, 2017-18:182).

Bugün bu olumsuz gelişmelere karşı, sanat yapıtlarında tepkiselliğin hâkim olduğu bir üretim biçimiyle doğanın ele alınıyor olması çok olası görülmektedir. Küresel ısınma, savaşlar, teknoloji ve bilimde yaşanan gelişmeler gibi bugün yaşamın iyiliği ve kötülüğünü belirleyen unsurlar üzerinde düşünüldüğünde, sanatçıların doğayı ele alış biçimlerinde tepkiselliğin bilinçli bir tercih olduğu söylenebilir. Bu tepkisellik, her zaman eylemsel, katı, sert bir dille değil, bazen de yapıtın alt metninde algılanarak, yapıtın üretim felsefesi ve sergileme biçimiyle, temsili üzerinden görünür olabilir. "Aslında sanatçıların çoğu, Pandora'nın Kutusu'ndaki kötülükler gibi, bilim ve teknolojinin sonuçları dünyaya yayılınca eski duruma tekrar dönülemeyeceğinin ve bu yüzden onların yarattığı sorunları çözecek derslere göre hareket etmeleri gerektiğinin bilincindedir" (Heartney, 2008:169).

Richard Long, Roxy Paine ve Olafur Eliasson'un bu bilinçle yapıtlarını ürettikleri ve yapıtlarında doğanın temsil edilme biçiminin; insan faktörüyle doğanın tahrip edilmesine, yaşanan çevre ve ekolojik sorunlara karşı bir refleks olarak geliştiği söylenebilir. Bugün doğa, sanatçıların genellikle olumladığı, öykündüğü hatta övdüğü bir şey olarak korunma altına alınmış gibidir. Bu üç sanatçının doğayı bir kesit olarak iç 
mekânda gösterme biçimleri de doğaya karşı hayranlık, övgü ve hassasiyetin bir parçası olarak korunaklı bir alan yaratma eğilimi olarak düşünülebilir.

\subsection{Mekanın içindeki ve dışındaki doğa: Richard Long}

Teknolojiye karşı doğayı savunan, doğanın gücü ve kutsallığına dair bir bilinç oluşturmak için ortaya atılan arazi sanatının önemli temsilcilerinden biri Richard Long'tur. Long, Afrika, İzlanda, Moğolistan, İngiltere, Japonya gibi ülkelerin dağlarında, su kenarlarında yani doğanın içinde çalışmalarını gerçekleştirir. Long'un çalışmalarını üretirken iyimser bir bakış açısıyla doğayla uyum içerisinde olduğu söylenebilir. Öyle ki doğada yaptığı bir yürüyüş bile bir sanat yapıtı olarak çalışmalarında vuku bulur. Sanatçının bu yürüyüşlerinde oluşturduğu sanat yapıtlarında doğaya herhangi bir nesne eklemediği, hal-i hazırda doğada bulunan doğal malzemelere biçim verdiği görülür.

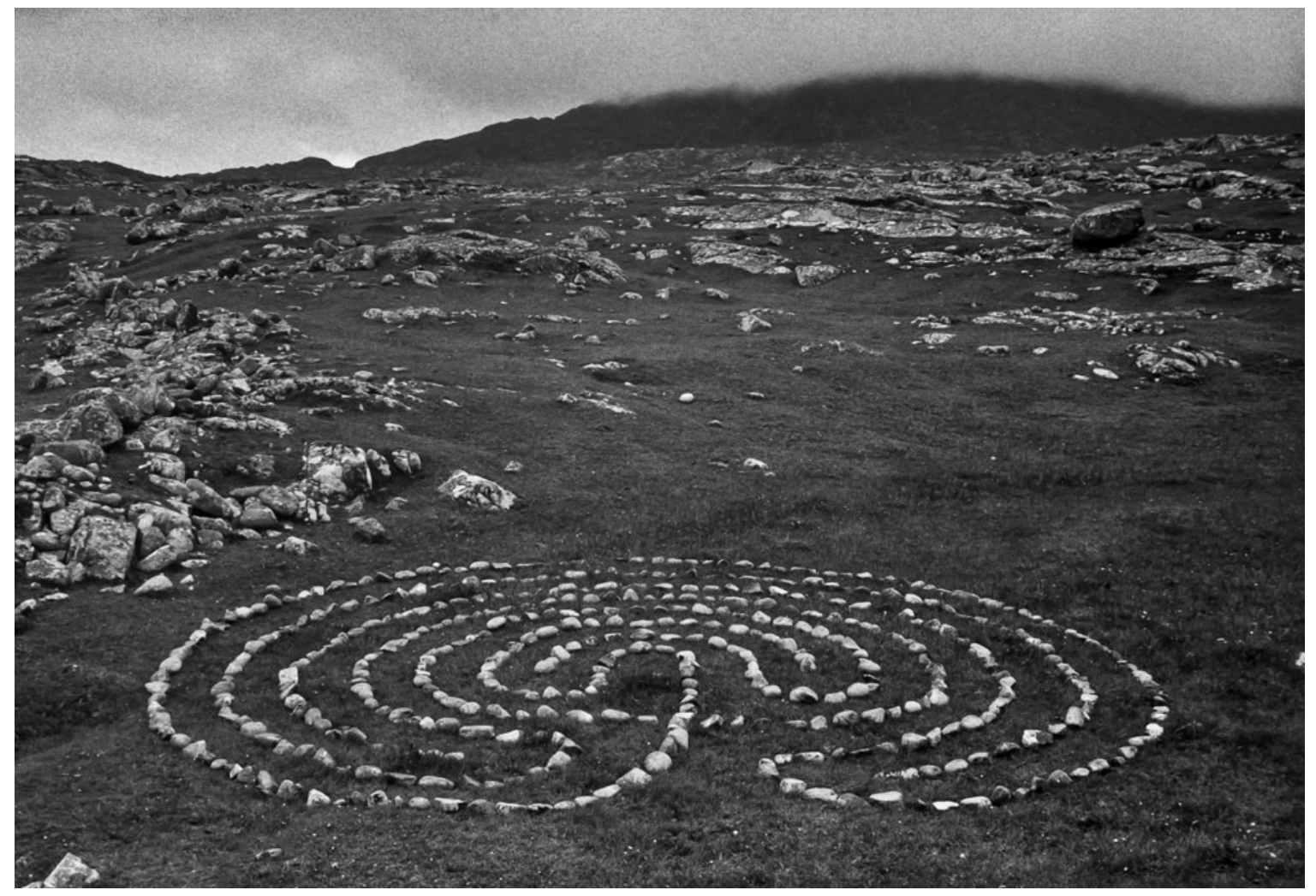

Görsel 1. Richard Long, Connemara Heykel, İrlanda 1971

Long'un doğaya karşı tavrının oldukça dikkatli, tutumunun oldukça duyarlı olduğu söylenebilir. Robert Smithson, Michael Heizer gibi diğer arazi sanatçılarının makine ve işçi kullanımını gerektiren anıtsal çalışmalarına göre Long, doğaya karşı daha romantik, nazik bir tavırla mütevazi çalışmalar gerçekleştirir (Kedik, 2010:109).

Long'un, doğada gerçekleştirdiği çalışmalarının yanı sıra doğa yürüyüşlerinden topladığı tahta parçası, taş gibi malzemelerle sergi mekanında gerçekleştirdiği çalışmaları da bulunmaktadır. Sanatını şekillendiren doğal malzemeler, duvarlara sürdüğü çamurlar doğanın, yapısına müdahale edilmeksizin iç mekana taşındığını gösterir.

"...Long, fotoğraflar ve çizimlerle belgelediği insansız manzaralarda yalnız yolculuklara çıkmıştır. Sanatçı doğada yaptığı değişiklikleri, galeri ortamında yeniden yarattığı yığınlar oluşturmak, taşlardan daireler ve çizgiler (...) meydana getirmekle sınırlı tutmuştur" (Heartney, 2008:169). Örneğin "Kırmızı Arduvaz Çemberi" adlı çalışması dışarıdan toplanmış kırmızı arduvaz taşlarının galerinin zemininde bir çember oluşturacak şekilde sergilenmesinden oluşur. Bu ve benzeri çalışmalarını, Jonathan Fineberg (2014:321) planlı bir 
INONU UNIVERSITY JOURNAL OF CULTURE AND ART / IJCA İnönü Üniversitesi Kültür ve Sanat Dergisi Volume/Cilt: 6 No/Sayı: 1 (2020) 14-26

rastlantısallık olarak 18. yüzyıl İngiliz Bahçelerine benzetir. 18. yüzyıl İngiliz bahçeleri, doğa anlayışının ilke ve yöntemlerinin uyarlandığı naturalizm akımıyla şekillendirilmiştir (Çetin, 2013). Bu anlamda Long'un, hem biçim hem yöntem olarak İngiliz bahçeleri gibi, doğayı odağına alarak galeri içerisinde doğal formlarla yapıtlarını gerçekleştirdiği söylenebilir.

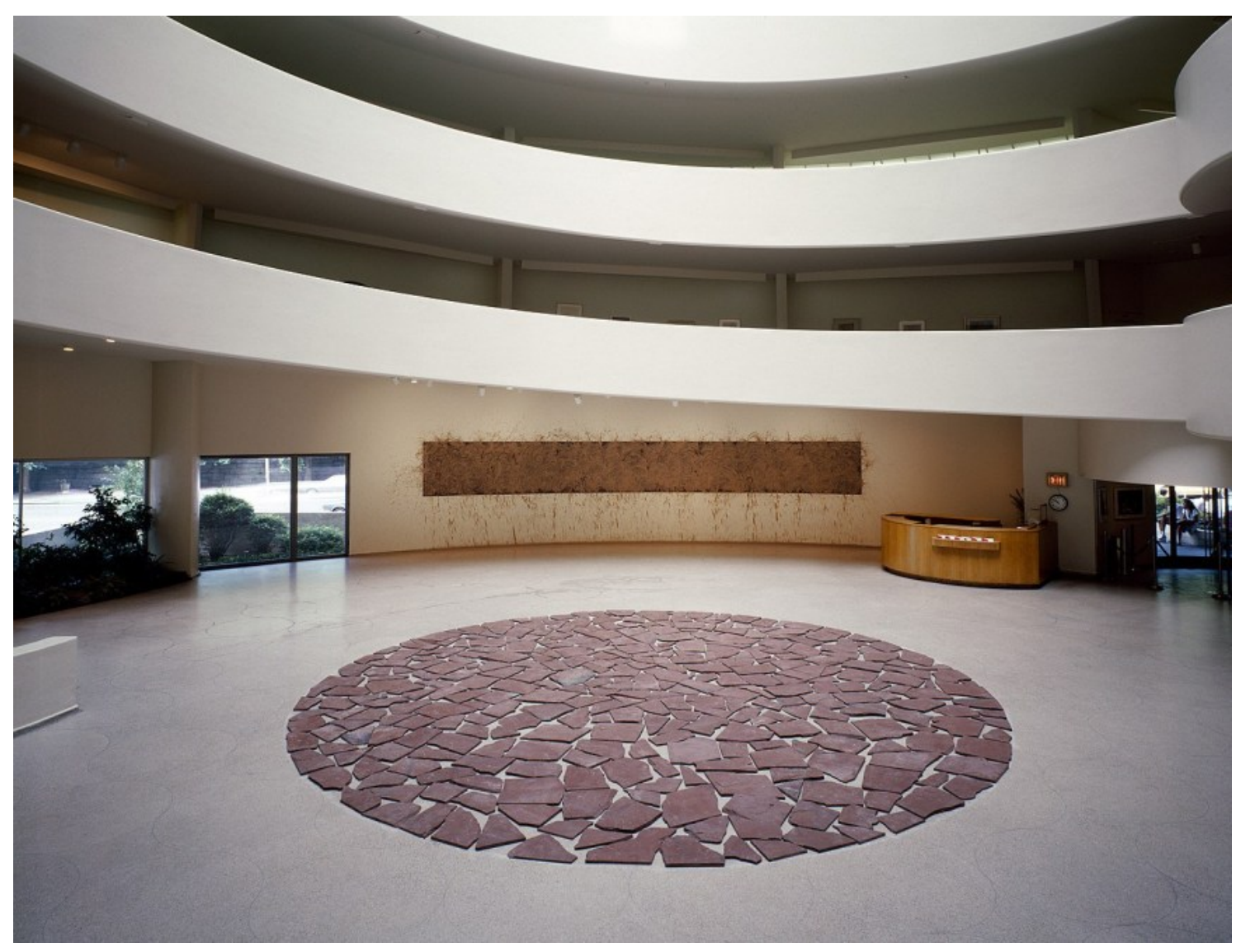

Görsel 2: Richard Long, Kırmızı Arduvaz Çemberi, 1980, Kırmızı Arduvaz, 8.53 m çapında

Fineberg'e (2014:194) göre Walt Whitman'dan Jackson Pollock'a Modern sanat, bireyin içinden doğan anlamlı şeylerin romantikliğine dayanır. Robert Rauschenberg ve Jasper Johns'un sanatı ise bir devre kartı gibi görünür. Bu esnada doğa kendindeki şeyler kadar şeylerin temsili anlamına da gelmeye başlar. Richard Long'un çalışmaları da doğada bulunan şeylerin temsili bağlamında değerlendirilebilir. Nihayetinde Long, doğadan aldığı malzemelerini yeni bir biçimle, yeni bir estetik algı yaratarak sunmaktadır. 


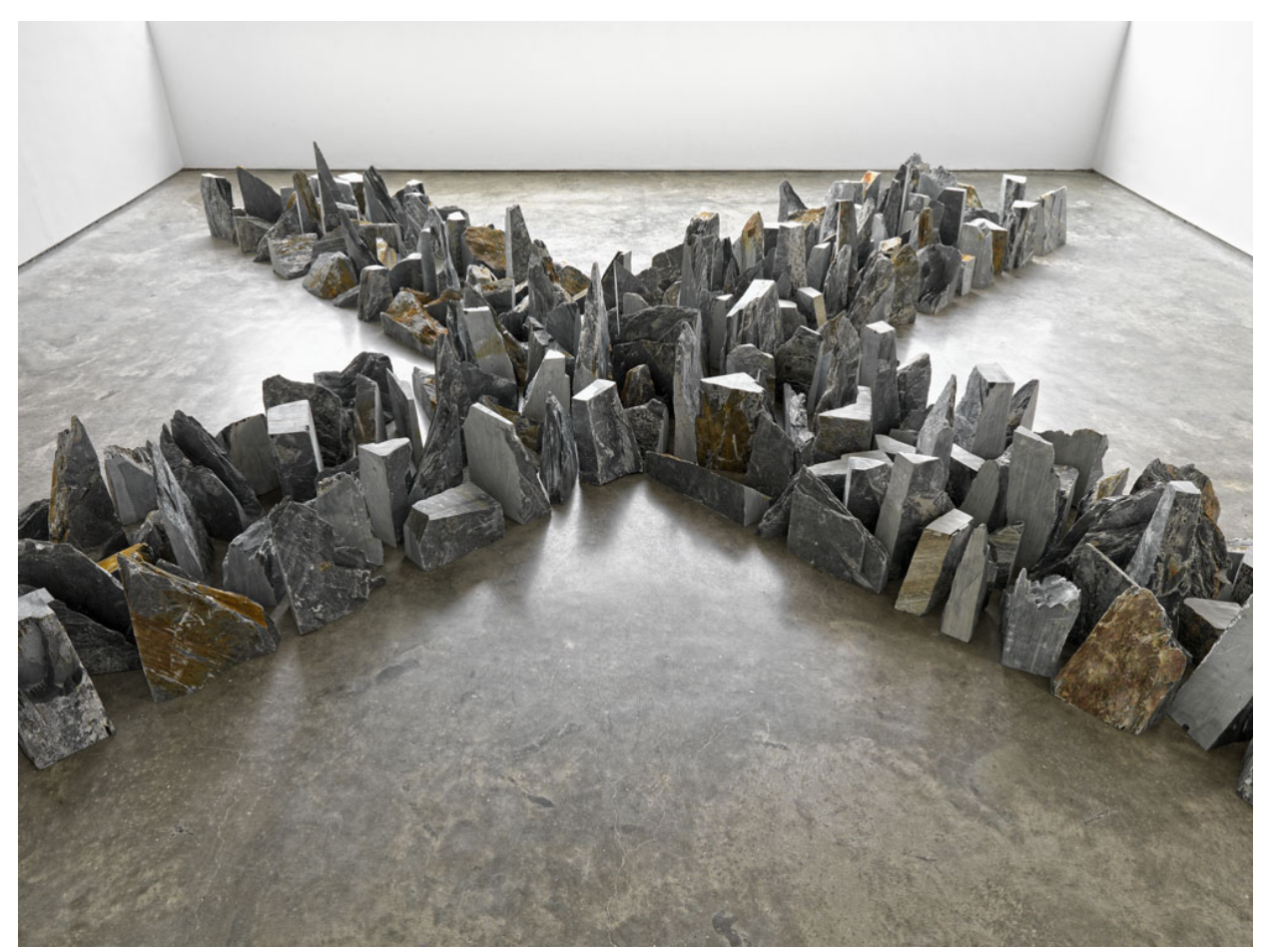

Görsel 3: Richard Long , Dört yol, 2014, Lisson Galeri, Londra

Doğanın gücüne inanmakla birlikte arazi sanatı, sanat mekanlarına, kurumlarına karşı bir tavır olarak da ortaya çıkmıştır (Antmen, 2013). Bu tavır doğrultusunda doğaya zarar vermeden doğayı sanatsal olana dönüştürme ya da doğadan sanata aktarma şeklinde çalışmalar yapılmıştır. David Hopkins (2018:176) Long'un "Yürümek İçin Yapılmış Hat" çalışmasında araziye iz bırakan bir sanatçı olarak çok fazla müdahalede bulunmadığını; ancak bu yapıtların estetiğin güvenli kollarına kaçmak gibi romantik bir arzuyu bünyesinde barındırdığını söyler. Estetiğin güvenli kollarının en doğrudan, anlaşıır ve hatta güvenli yeri olarak bir galeri düşünülürse, Long'un çalışmalarını iç mekanda sergileme pratiği de daha anlaşılır olabilir.

\subsection{Yapay doğa: Roxy Paine}

Roxy Paine, çalışmalarını doğanın karmaşık bir sistem içinde sürdürdüğü varlığı ve insanın bu sistemle mücadelesi üzerine temellendirir. Doğa karşısında insan zihnini istikrarsız olarak görür. Çalışmalarında dış mekanı içeride yeniden var ederken, yapay bahçeler kurgular. Polimer reçine ile şekillendirdiği her bir doğa parçasını titizlikle boyar. Adeta dış mekandan sökülüp içeriye konulmuş görüntü ile bizi karşı karşıya bırakır. Bu üretim biçimiyle ruhsal, içsel alanımız ve gerçeklik algımıza bir nevi saldırıda bulunduğu söylenebilir.

Örneğin 1997 tarihli "Zehirli Sarmaşık Tarlası" adlı yapıtında karahindiba, kokulu lahana, kınkantalılar ve çimenlerden oluşmuş bir vitrin tasarlar. Bir canlı olarak büyümüş ve büyüyecek olan doğa, bir toprak parçası üzerinde görünür. Fineberg (2014: 497) bu görünümü, doğal tarih müzesinde görülebilecek şeyler olarak tanımlar. Doğa tarihi müzelerinin doğa varlıklarını sergileyen, öğretici bir kurum olma özelliğinden hareketle bu benzetme çok makul görülebilir. Nitekim Paine'nin de çalışmalarında doğadan bir kesit sunarken doğaya karşı öğretici bir tutum sergilediği söylenebilir. 


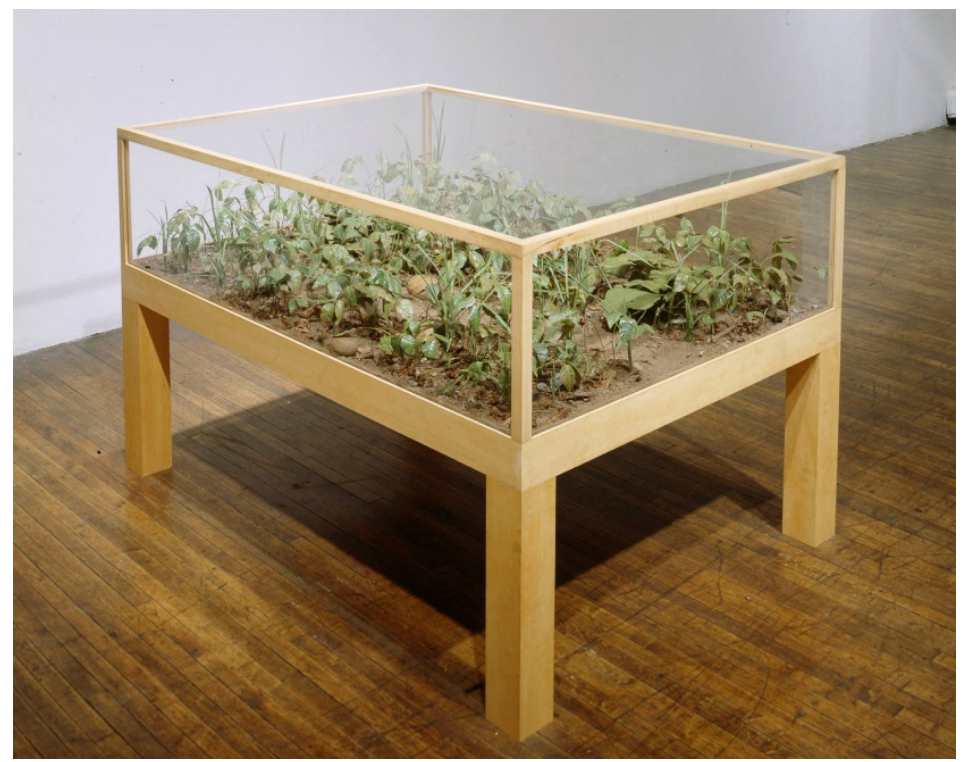

Görsel 4. Roxy Paine, Zehirli sarmaşık tarlası, 1997, 121x167 x121 cm.

Heartney'e (2008:184) göre Paine çalışmalarında zehirli mantarlar ya da bahçe otlarından tarlalar yapmakta, onlara zehirli, ota boğulmuş gibi isimler vererek uyumsuzca, temiz, beyaz galeri mekanlarına yerleştirmektedir. Paine böylece, doğal dünyanın kullanımı ve kötüye kullanımı hakkında yeniden düşünmemizi istemektedir. Onun bütün çalışmaları, insanın çevresini denetleme arzusu ile doğanın bu tür arzulara karşı koyan karşıtıkları arasındaki içsel çatışmayı konu almaktadır.

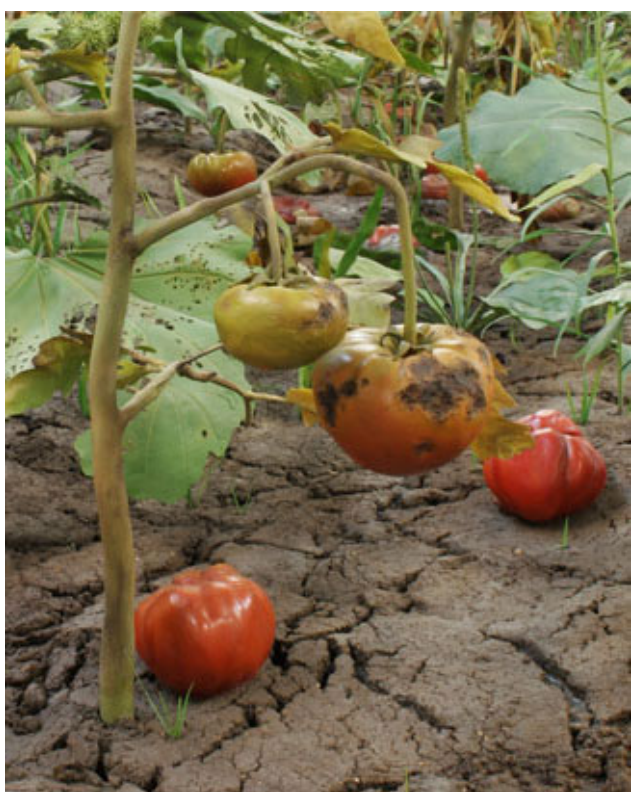

Görsel 5: Roxy Paine, Ota boğulmuş bahçe, 2005, Termoset plastik, polimer, yağlı boya, PETG, paslanmaz çelik, lake, epoksi, pigmen, $160 \times 363 \times 175 \mathrm{~cm}$ (detay)

Paine'nin bir başka yapıtı ise "Afyon Çiçekleri" tarlasıdır. 1.82 metreye 2.43 metre genişliğindeki yapay toprak üzerindeki tomurcuk halinde ya da açmış şekilde görünen çiçekler doğal süreci gösteren bir anlayışla yapılmıştır. Bu çalışmada, doğanın, içerik ve biçim olarak tüm gerçekliğiyle algılanmasına rağmen bir simülarkdan ibaret olduğu söylenebilir. Fineberg (2014:497), bu bitki simülarkının makinelerle estetik bir devamlılık sağladığını söyler. 


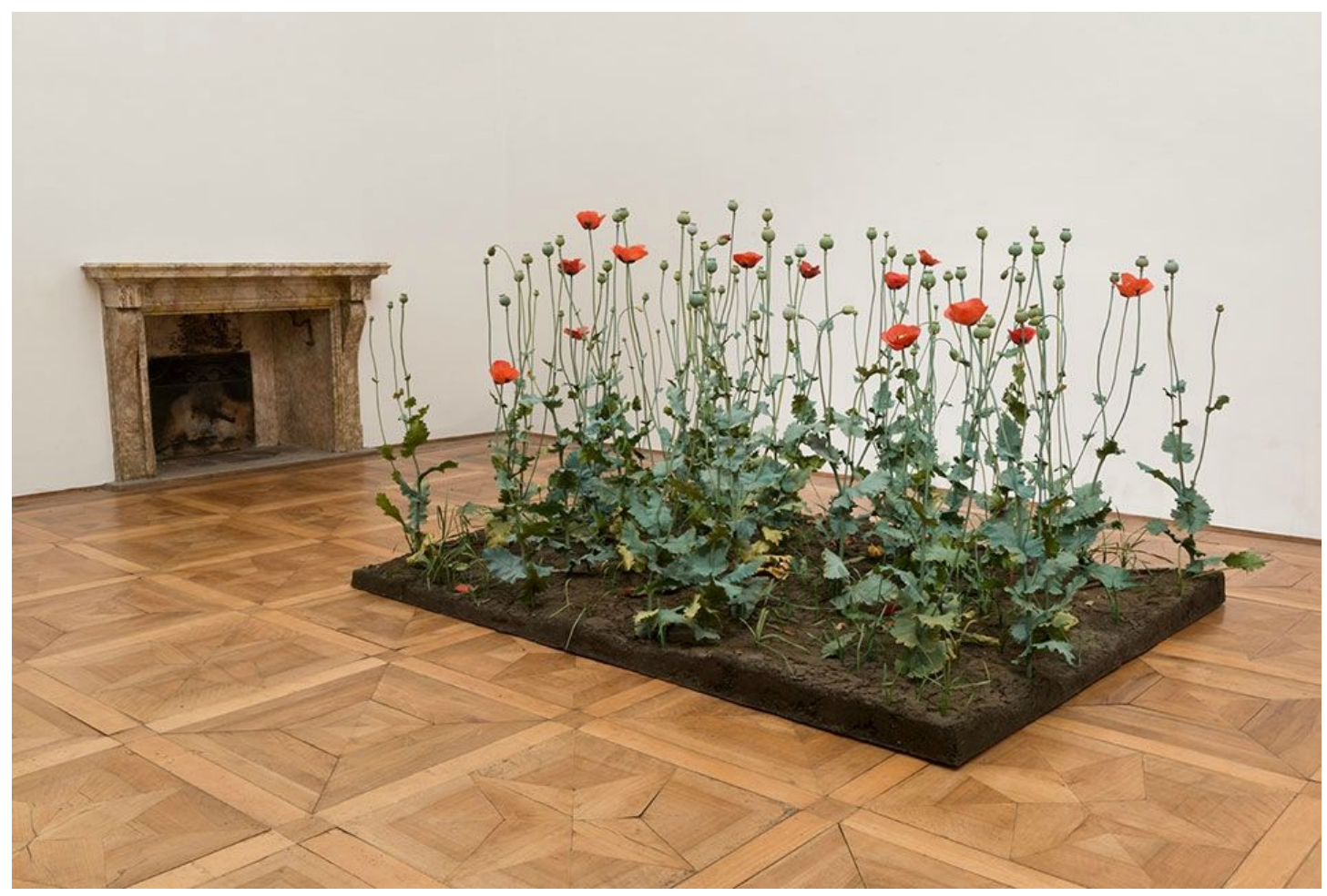

Görsel 6. Roxy Paine, Ekin (Afyon çiçekleri),1997-1998

Paine bir botanik bilimci gibi çalışır. Bitkilerin karşılıkları ve alt anlamlarıyla çalışmalarını yürütür ve bitkilerin potansiyellerini bir metafor olarak kullanılır.

\subsection{Fantezi manzaraları: Olafur Eliasson}

Olafur Eliasson doğanın korunmasına, doğa ve insanın geleceğine odaklanan bir aktivist olarak kabul edilebilir. Çalışmalarını doğa ve doğanın algılanışı üzerinden dünyanın daha yaşanabilir, daha iyi bir yer olması fikriyle kurgular. Genellikle, izleyicilerin doğanın tahrip edilmesi, çevre kirliliği, ekolojik sorunlar hakkında insanın rolü, etkisi üzerine kendilerini sorgulayabilecekleri atmosferler yaratır. Yeşil Nehir (1998), Sis montajı (2016), Şelale (2016) gibi çalışmalarında bu atmosfer dış mekanda yaratııırken; Sarı Orman (2017), Hava Projesi (2003) ve Nehir Yatağı (2014-2015) çalışmalarında dışarıya dair manzaralarla iç mekanda yaratılır. Bir doğa kesitinin iç mekanda yeniden yaratılmasının, insanların alışık oldukları görüntülere, olaylara verdikleri sıradan tepkileri ters yüz ettiği söylenebilir. İzleyici, içeride karşılaştığı doğa hakkında yeniden düşünebileceği, yeniden izleyebileceği, farkındalığının artacağı bir sürece girebilir.

Eliasson'un "Nehir Yatağı" çalışması bu çalışma disiplinine dair önemli bir örnek olarak görülebilir. Nehir Yatağı, içinde gezilebilecek, bir nehir yatağı çevresindeki engebeli arazide yürümenin deneyimlenebileceği bir iç mekan manzarasıdır. İçeri, dışarının doğal şartlarıyla şekillendirilmiştir. Louisiana Müzesi'nde gerçekleştirilen çalışma doğal dünya ile insan yapımı dünya arasındaki çizgileri bulanıklaştırmak üzerine bir kurgudur. Dışarıda hiç umursamadan üzerine basılabilecek doğanın, iç mekanda üzerine basılan bir sanat yapıtı olarak sergilenmesiyle izleyiciye yeni bir düşünme ve sorgulama alanı oluşturduğu söylenebilir. Böylelikle, günlük hayatında çevre kirliliğini normalleştiren izleyicinin, sergi mekanında yeni bir görme ve anlamlandırma deneyimi yaşadığı düşünülebilir. 
INONU UNIVERSITY JOURNAL OF CULTURE AND ART / IJCA

İnönü Üniversitesi Kültür ve Sanat Dergisi

Volume/Cilt: 6 No/Sayı: 1 (2020) 14-26

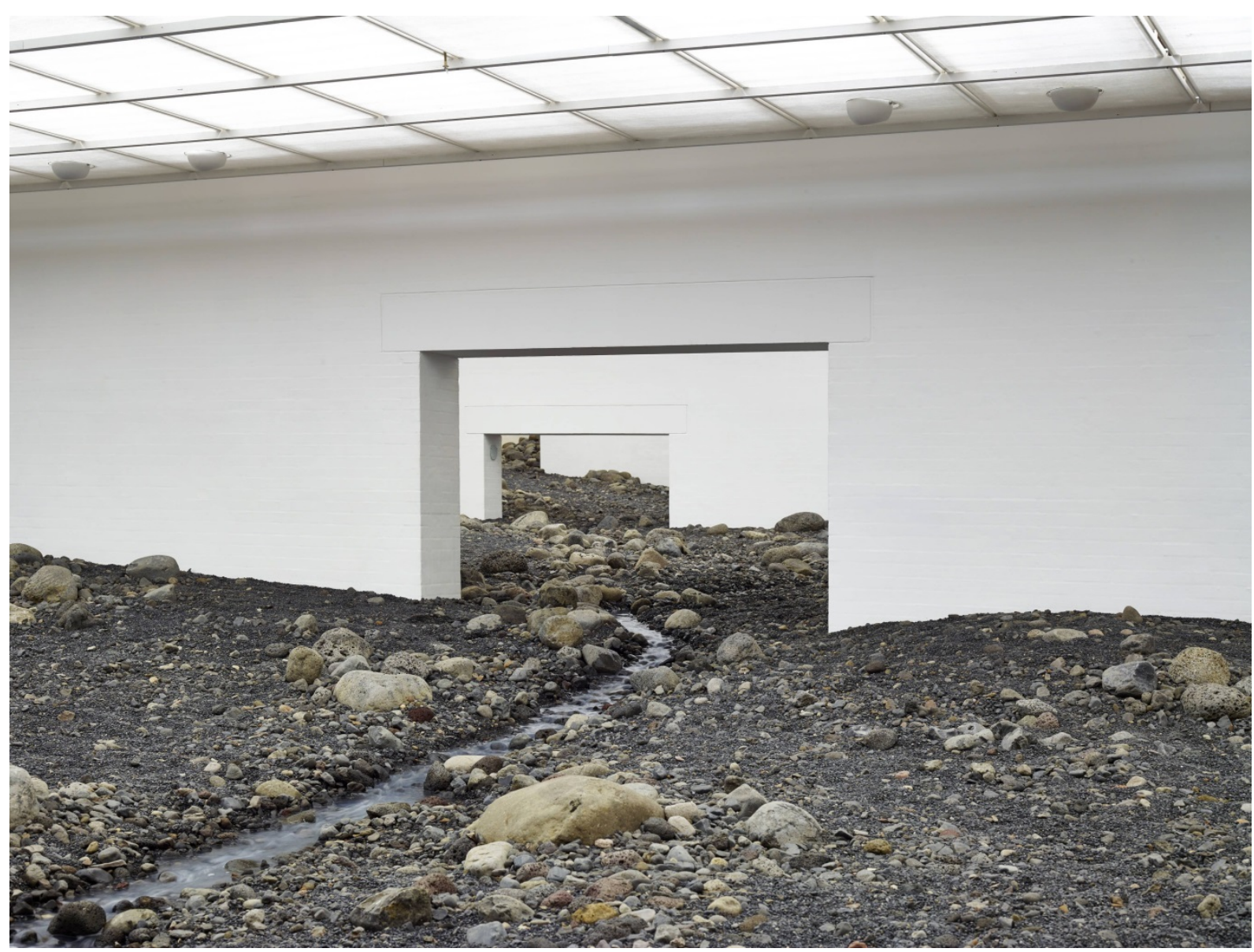

Görsel 7. Olafur Eliasson - Nehir Yatağı, Louisiana Modern sanat Müzesi, Danimarka, 2014-2015

Eliasson ve peyzaj mimarı Günther Vogt'un işbirliği ile üretilen "Sarı Orman" çalışması ise izleyiciyi doğaya daha derin bakacağı, doğayı odağına alacağı bir atmosfere çağırır. Bir çember içerisine yerleştirilmiş iki taraflı huş ağacı kümesinden oluşan çalışma, insanlara doğal bir ormanda gezme deneyimi sunuyor gibi görünse de, sarı monofrekans lambalarıyla yaratılan görsellik, yapay bir atmosfer oluşturur. İzleyici, yapay ve doğal olanı sorgulayacağı, algı karmaşası yaşayacağı, içeriye ve dışarıya ait olanı yeniden yorumlayabileceği, hem tanıdığı hem uzaklaştığı bir mekanda bulunur. "Algı değiştiren etkileriyle bu tür çalışmalar, bir yandan geleneksel tinsellikler ya da inanç sistemleriyle doğrudan bağı ortadan kaldıırken, öbür yandan günümüzün değişik bilinç formlarına yönelik arayışlarının alanını genişletmektedir" (Heartney, 2008:287). 


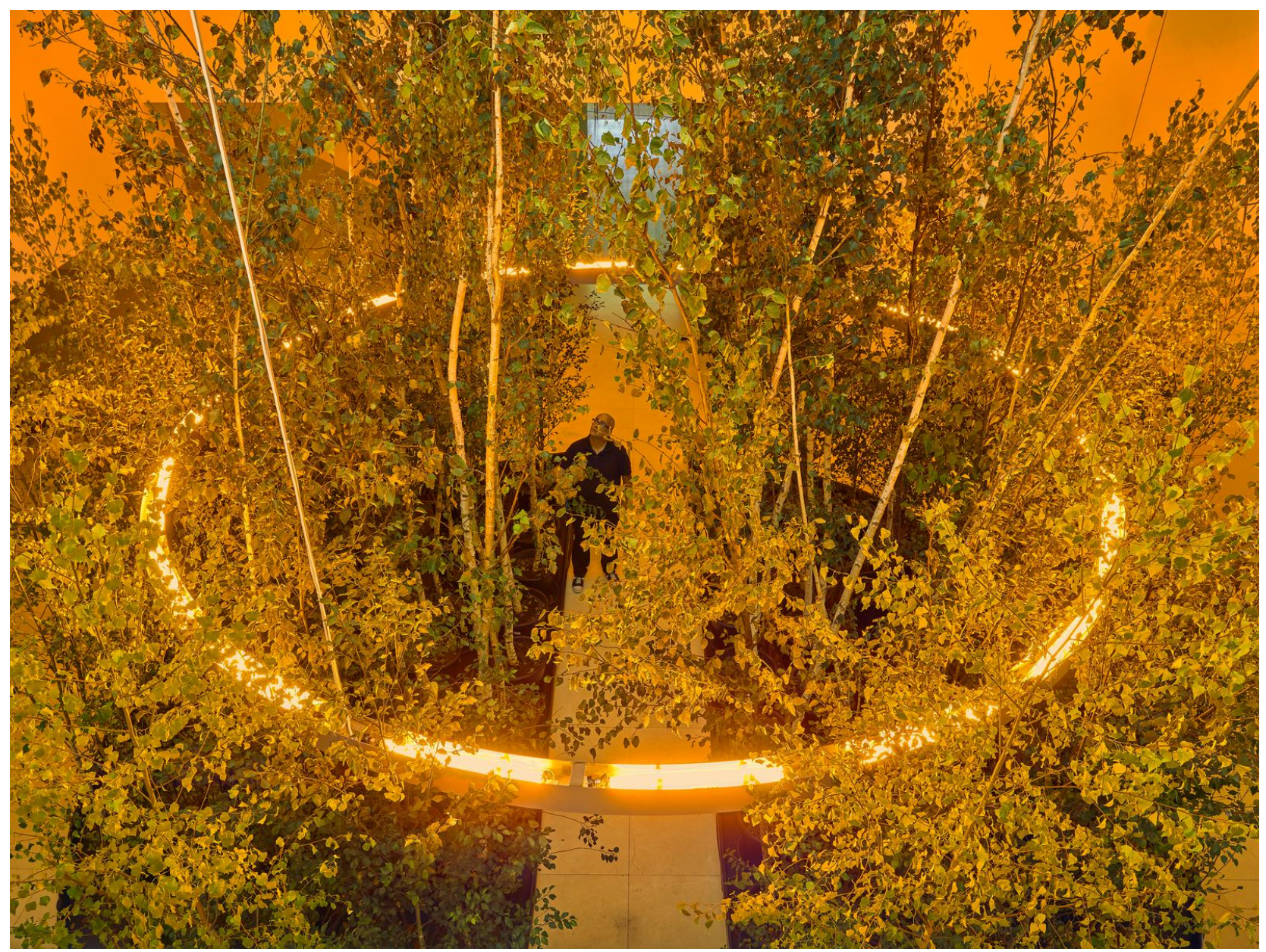

Görsel:8 Olafur Eliasson, Sarı orman, 2017, Serralves Çağdaş Sanat Müzesi, Fotoğraf: Filipe Braga

Eliasson'un en etkili yapıtlarından birinin "Hava Projesi" olduğu söylenebilir. Çalışma, Londra Tate Modern'in Türbin salonunda gerçekleştirilir. Salonda izleyicileri karşılayan yarı dairesel, yüzden fazla ampulle üretilen güneş şekli, ayna kaplı tavanda görünür. Mekan ise, su buharı ve şeker bileşiminden oluşan sisle doldurulur ve dış mekanın hava şartlarına dair tanımlamaları -soğuk bir kış günü- iç mekanda izleyicinin algısına bırakır. Burada, doğanın gücünün, büyüklüğünün ve etkileyiciliğinin iç mekanda gösterilmesi Eliasson'un çalışmalarında yarattığı fantastik atmosferi daha anlamlı hale getirir. Wilson, bu atmosferi zamanla ilişkilendirir. "Hava Projesi manzaranın temel fiziksel öğelerine ilişkin deneyimlerimizi irdelerken bir yandan da zamandan bağımsız, hatta tuhaftır; zamansız bir mekan, gelip geçici bir rüya ve fantezi bölgesi gibi de işlev görür" (Wilson, 2015:128). Edward A. Shanken ise Hava projesini teknoloji, bilimsellik ve romantize bakış açısının birlikteliği üzerinden yorumlar. "Elliasson burada, doğal fenomenlerin aşkın karşılaşmalarına romantize bakış ile bilimsel nesnelliğin ve onunla ilintili teknolojik medyaların rasyonalize yöntemleri arasındaki gerilimle ustaca oynar" (Shanken, 2012: 76). 


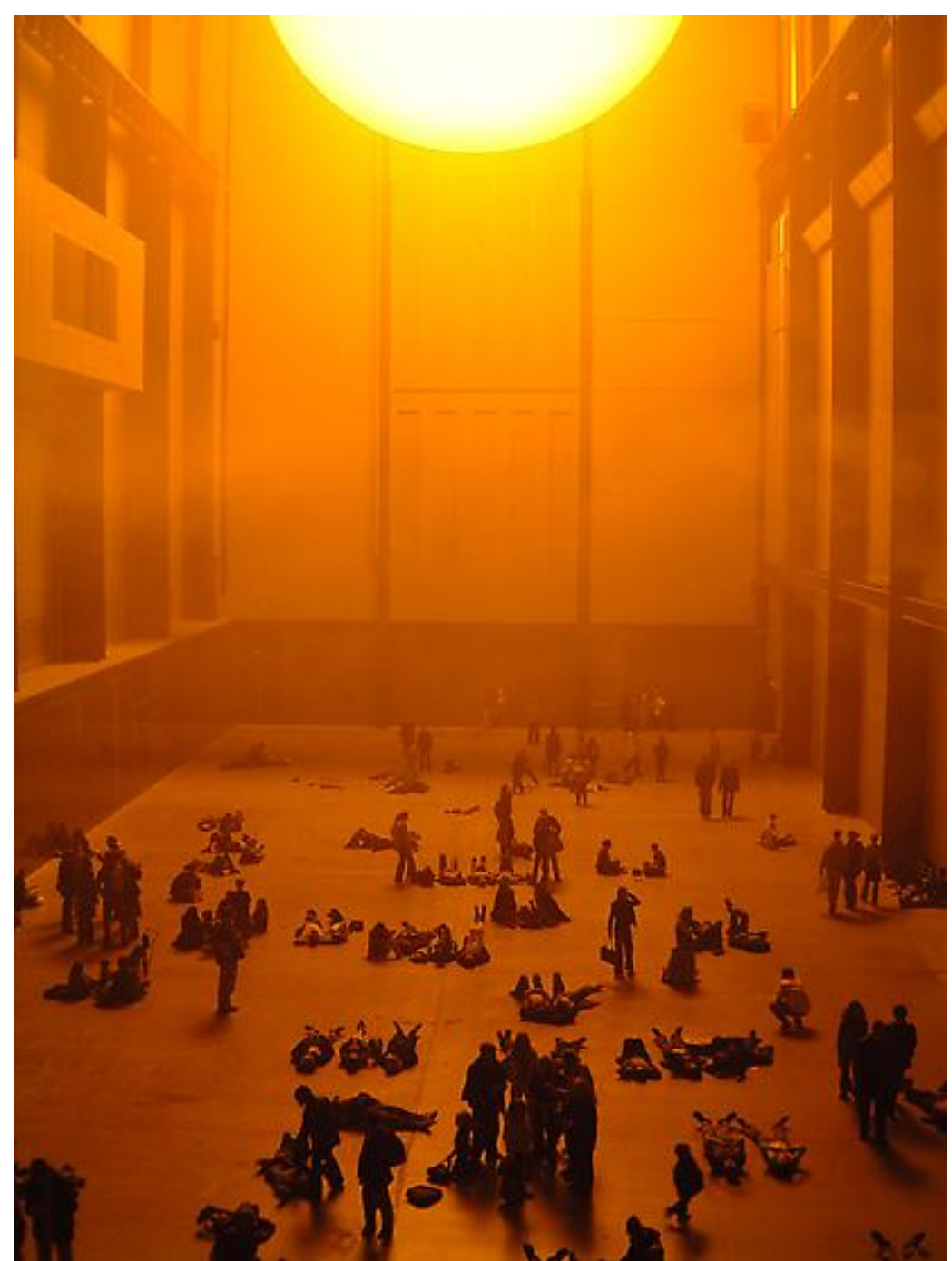

Görsel 9. Olafur Eliasson, Hava projesi, Türbin Salonu, Tate Modern, Londra 2003

\section{Sonuç}

1960'lar ve sonrasıyla sınırlandırılmış olan çalışmada, üç sanatçı seçilerek doğanın iç mekanda olduğu gibi gösterilmesi üzerinde durulmuştur. Öncelikle sanatçıların yaşadıkları dönemin sosyal, politik, ekonomik atmosferi ile çevresel ve ekolojik sorunları açıklanmıştır. Daha sonra sanatçıların yapıtları üzerinden doğayı algılama, yorumlama ve sergileme yöntemleri incelenmiştir.

Bu çerçevede, sanayi devrimiyle hız kazanan çevre sorunlarının, 1960'lar ve sonrasında daha da arttığı, bununla birlikte doğa-insan ilişkisi dolayısıyla doğa-sanat ilişkisinin farklı bir boyuta taşındığı görülmüştür. Sanatta doğa, estetik bir kaygı olmanın ötesinde çevresel ve ekolojik sorunlara dair farkındanlık yaratacak, duyarlık oluşturacak bir mecra, konu haline gelmiştir. Bu dönemde sanatçılar, çevre ve ekolojik sorunları görmezden gelmemişler, doğanın tahribine karşı eleştirel bir dili sanat dili olarak benimsemişlerdir. Dönemin öncü sanatçılarının yapıtlarına bakıldığında bu durum daha görünür olmaktadır. Ayrıca bu dönemde doğanın sanatta yer alma biçimlerinden birinin, doğanın kendisi olarak iç mekanda sergilenmesi olduğu görülmüştür.

Yapıt açıklamalarına ve sanat anlayışlarına yer verilen Richard Long, Roxy Paine, Olafur Eliasson, 1960'lar ve sonrası dönemde, yani altmış yıllık zaman diliminde yaşayan ve bu üretim mantığıyla yapıtlarını gerçekleştiren sanatçılar arasından seçilmiştir. Üç sanatçının yapıt okumaları yapıldığında, üretimlerinin dönemin ruhuna, üretim ve sergileme biçimlerine paralel olarak şekillendiği; daha özelde ise sanat 
yapıtlarının şekillenme ve sergilenme biçimlerinde doğanın gücü, doğanın karmaşıklığı ve doğa sistemleri üzerinde durdukları görülmüştür.

Richard Long'un doğadan topladığı malzemeleri iç mekanda sergilemesinin, galerinin bilinen bir sergileme yeri olarak estetik kaygılarına karşılık gelmesiyle ilişkili olduğu; Roxy Paine'in doğal olan ve yapay olan arasındaki çelişkiyi deneyimlettiği, böylece doğanın yüceliği ve önemi hakkında bir farkındalık yarattığı; Olafur Eliasson'un ise dış mekana dair olan manzaraları iç mekanda sergilemesinin izleyiciye üzerine bastığı doğa hakkında düşünme fırsatı, kendini sorgulama fırsatı verdiği sonuçlarına varılmıştır.

Sanatçıların doğayı algılama ve yorumlama biçimlerinin, üretimlerinde doğanın görünme biçimlerini de değiştirdiği; üç sanatçının da doğaya karşı hayranlık ve övgüyle, doğaya dair farkındalık oluşturmak adına doğayı bir kesit olarak iç mekana taşıdıkları; doğayı yanılsama ve temsilden uzak gerçek bir kesit olarak iç mekana taşımanın doğaya karşı hayranlık, övgü ve olumlama vurgusunu artırdığı, iç mekanın korunaklı bir alan olarak tüm bu duyarlıkları vurgulayacak bir imkan oluşturduğu görülmüştür.

\section{Kaynakça}

Antmen, A. (2013). Sanatçılardan Yazılar ve Açıklamalarla 20. Yüzyıl Batı Sanatında Akımlar. İstanbul: Sel yayıncılık.

Benjamin, W. (2018). Brecht'i Anlamak. (G. I. Haluk Barışçan, Çev.) İstanbul: Metis Yayınları.

Berger, J. (2019, Mayıs 09). Manzaralar. (B. Eyüboğlu, Ö. Dalkıran, O. Tecimen , \& E. Gen, Çev.) İstanbul: Metis Yayınları.

Çetin, U. (2013). İngiliz Bahçe Sanatı. Meriç Uluslararası Sosyal ve Stratejik Araştırmalar Dergisi, 2(4), 1-19.

Çoşkun, Z. (2019). 21. Yüzyılda Sanat...? Kurumlar, Illetişim ve Yönetim. İstanbul: İkaros Yayınları.

Fineberg, J. (2014). 1940'tan Günümüze Sanat. (G. E. Yılmaz, Çev.) İzmir: Karakalem Kitapevi yayınları.

Greenpeace. (2020, Şubat 18). https://www.greenpeace.org/turkey/kesfet/ adresinden alınmıştır

Heartney, E. (2008). Sanat ve doğa ile Teknoloji- Arazinin ve Bedenin Yeniden İnşası. E. Heartney içinde,

Sanat ve bugün (O. Akınhay, Çev.). İstanbul: Akbank Kültür ve Sanat Dizisi.

Hopkins, D. (2018). Modern Sanattan sonra 1945-2017. İstanbul: Hayalperest Yayınları.

Karakitapoğlu, E. B. (2017, Kasım 27). İklim Göçmenleri. (Ö. Madra, Röportaj Yapan) Açık Gazete.

Kedik, A. S. (2010). Richard Long: Bir Yürüyüşün İma Ettikleri. Sanat ve Tasarım Dergisi, 1(5), 107-120.

Leppert, R. (2017). Sanatta Anlamın Görüntüsü. İstanbul: Ayrıntı Yayınları.

Shanken, E. A. (2012). Sanat ve Elektronik Medya. İstanbul: Akbank .

Turan, A. (2016, Aralık 13). Ekolojik Sanata Göz Kırpan Bir Sergi. Ekim 23, 2019 tarihinde artfulliving: https://www.artfulliving.com.tr/sanat/ekolojik-sanata-goz-kirpan-bir-sergi-i-9559 adresinden alındı

Wallace, M. (2017-18, Kasım-Aralık-Ocak). "tuhaf bir Ekoloji":doğasını bozduğumuz Bir doğanın Doğası. Doğu Batı Düşünce Dergisi(83).

Wilson, M. (2015). Çağdaş Sanat Nasıl Okunur 21. Yüzyıl Sanatını Yaşamak. (F. C. Erdoğan, Çev.) İstanbul: Hayalperest Yayınevi.

\section{Görsel Kaynakça}

Görsel 1. https://tr.pinterest.com/pin/179088522653415804/ 


\section{INONU UNIVERSITY JOURNAL OF CULTURE AND ART / IJCA}

İnönü Üniversitesi Kültür ve Sanat Dergisi

Volume/Cilt: 6 No/Sayı: 1 (2020) 14-26

Görsel 2. https://www.guggenheim.org/artwork/2543

Görsel 3. http://www.richardlong.org/

Görsel 4. http://www.josephketner.com/acquisitions/

Görsel 5. https://mocoloco.com/weed-choked-garden/

Görsel 6. https://tr.pinterest.com/pin/672654894317421022/

Görsel 7. https://publicdelivery.org/olafur-eliasson-riverbed/

Görsel 8. https://olafureliasson.net/archive/artwork/WEK110709/yellow-forest\#

Görsel 9. http://www.tanyabonakdargallery.com 